\title{
Synthesis of Macrocyclic Ionophore for the Development of Highly Selective Chloride Sensor
}

\author{
SAMEENA MEHTAB* and TANVEER IRSHAD SIDDIQI \\ Department of Chemistry, Lovely Professional University, Punjab - 144806, India. \\ ${ }^{*}$ Corresponding author E-mail: sameena.17937@ Ipu.co.in \\ http://dx.doi.org/10.13005/ojc/310121
}

(Received: January 10, 2015; Accepted: February 08, 2015)

\begin{abstract}
The macrocyclic ligands 3,8,12,17-tetramethyl-2,18,9,11-bipyridyl-1,4,7,10,13,16hexaazacyclooctadecanetetrahydro bromide has been synthesized and explored as suitable ionophores for chloride selective membrane sensors. It displays Nernstian behavior $(59.2 \mathrm{mV}$ decade $^{-1}$ ) across the range of $4.1 \times 10^{-8}$ to $1.0 \times 10^{-2} \mathrm{M}$. The detection limit of the electrode is $\sim 15$ $\mathrm{nM}$ and the response time and life times are $14 \mathrm{~s}$ and eight weeks respectively over a wide $\mathrm{pH}$ range (3.5 - 9.5). Interference from other anions is very low and it can be used as indicator electrode in the potentiometric titration of chloride ions and to determine chloride in agricultural soil water samples.
\end{abstract}

Key words: Chloride Membrane Sensor; Ion-Selective Electrode; Macrocyclic Ionophore.

\section{INTRODUCTION}

The determination of the concentrations of ionic species in aqueous samples is important in many areas of applied analytical chemistry, e.g., in process control, and in the analysis of clinical, horticultural, or environmental samples. The ionselective electrodes are of widespread interest as they provide a rapid, accurate, reproducible, selective, and low-cost analytical method of specific guests ${ }^{1}$. ISEs are also of obvious interest because they can help translate the chemistry of new substrate binding systems into tools that can be used to recognize selectively various targeted species in the presence of potentially interfering analytes. Anions show a wide range of shapes and geometries and a lot of them are $\mathrm{pH}$-sensitive, factors that have to be taken into account when designing a specific anion host. Anion receptors thus use binding forces that typically involve hydrogen bonding, electrostatic interactions and coordination to suitable metal centre. The effective 
anion-selective electrode should incorporate a selective ionophore for a guest anion in its membrane matrix ${ }^{2}$

Among inorganic anions, $\mathrm{Cl}^{-}$anion is particularly important as it plays an important role in a variety of biological ${ }^{3}$ and physiological processes $^{4}$, clinical diagnosis 5 , environmental monitoring $^{6}$ and industrial applications ${ }^{7-9}$. Furthermore, its metabolic imbalance in blood and other body fluids results in various diseases and pathological disorders such as stroke, edema, cystic fibrosis, and atherosclerosis. With a continuous emergence of numerous ionophores, great progress has been made in the research in the direct detection of chloride concentration and potentiometric titration. As an electro active material in an electrode, the ionophore plays a crucial role in determining the performance characteristics of ion selective sensors. Some anion exchangers ${ }^{10,11}$ have been used as $\mathrm{Cl}^{-}$anion-selective ionophores but often lacked selectivity toward $\mathrm{Cl}^{-}$anion over other lipophilic anions such as $\mathrm{NO}_{3}{ }^{-}$and $\mathrm{ClO}_{4}$. Lewis acid macrocycles ${ }^{12}$ and lanthanide tris(âdiketonates) have also been utilized to prepare $\mathrm{Cl}^{-}$ anion-selective electrodes that suffered from significant interference from $\mathrm{I}, \mathrm{Br}$, and $\mathrm{SCN}^{-}$ anions ${ }^{13,14}$. Several other strategies are followed to design an ionophore with variety of functionalities which can compliment with the shape and size of an anion thereby showing selectivity towards a particular anion, like, 2,5-dihydroxy-pbenzoquinone ${ }^{15}$, Polypyrrole-graphite- epoxy composite $^{16}$, Amino methylated polystyrene salicylaldehyde schiff base Co(II) complex ${ }^{17}$, Calix ${ }^{4}$ arene derivative with ureido moiety ${ }^{18}$, Tridodecylmethyl ammonium chloride ${ }^{19,20}$, hydrogen bond forming ionophores ${ }^{21,22}$, and epoxy resins ${ }^{23}$. Though many species have been examined as potential chloride ionophores, only few have yielded requisite chloride selectivity to be used in the preparation of membrane electrode.

For better performance the ionophore ought to preferentially bind with the target ion and should possess a high degree of its own photochemical and redox stability. Therefore, it is not surprising that the robust macrocycles and their metal derivatives, due to their rich coordination chemistry and structural diversity, have got much attention as ionophores for the selective recognition and sensing of cations and anions ${ }^{24-29}$. They are incorporated, as ion carrier agents, in suitable polymeric membranes to get the ion selective membrane electrodes. These electrodes respond selectively to the concentration changes of a particular cation or anion and thereby transduce the analyte ion activity into a potential read-out. Objective of the present paper is to synthesize a new highly selective ionophore and to optimize membrane compositions to achieve a chloride ion sensor of improved response characteristics. The 3,8,12,17-Tetramethyl-2,18,9,11-Bipyridyl$1,4,7,10,13,16$-Hexaaza Cyclooctadecane Tetrahydro bromide (Scheme. 1) represent a class of macrocycle that should act as anion binding agents $^{30,31}$. In this anion-receptor interactions of macrocyclic ionophore are expected to reflect contributions from both electrostatic and hydrogen bonding interactions in varying degrees depending on the conditions (e.g., degree of protonation, nature of solvent, etc.) Because of this potential duality, it was proposed that studies of appropriately chosen analytes, capable of multiple types of supramolecular interactions, would provide invaluable insights into the fundamental molecular recognition properties of this class of receptor.

\section{EXPERIMENTAL}

\section{Reagents}

Reagent grade hexadecyl trimethylammonium bromide (HTAB), dibutylphthalate (DBP), benzyl acetate (BA), dioctylphthalate (DOP), tributyl phosphate (TBP), dioctyl phthalate (DOP), o-nitrophenyloctyl ether (oNPOE), tetrahydrofuran (THF), barium chloride dihydrate $\left(\mathrm{BaCl}_{2} \cdot 2 \mathrm{H}_{2} \mathrm{O}\right)$ sodium borohydride $\left(\mathrm{NaBH}_{4}\right)$, ethylenediamine, hydrobromic acid, and high molecular weight poly(vinylchloride) were purchased from E. Merck (Germany) and used as received. 2,6-Diacetylpyridine and methylacrylate acrylonitrile were procured from S. D. Fine-chem. Ltd. Sodium salts of all anions used were of analytical grade and used without any further purification. The solutions of anion salts were prepared in milliipore water and standardized whenever necessary.

\section{Apparatus}

Carbon, hydrogen, and nitrogen were 
analyzed with a Vario EL III elemental analyzer after carefully dried samples under vacuum for several hours. The UV-Vis spectra were recorded on PerkinElmer Lambda 35 UV/Vis spectrophotometer. IR spectra were obtained on a Thermo Nikolet Nexus FT-IR spectrometer in $\mathrm{KBr}$. Room temperature magnetic susceptibility measurements were done on a Princeton applied research vibrating sample magnetometer Model. All potential measurements were performed at ambient temperature using a Century scientific-digital $\mathrm{pH} /$ millivolt-meter.

Synthesis and Characterization of $3,8,12,17$ Tetramethyl-2,18,9,11-Bipyridyl-1,4,7,10,13,16Hexaaza Cyclooctadecane Tetrahydrobromide as Macrocyclic Ionophore

To synthesize macrocyclic ionophore (MI) using well established $2+2$ template condensation method, followed by $\mathrm{NaBH}_{4}$ reduction of the imine as shown in the scheme 1 . $\mathrm{Ba}$ (II) was chosen as the templating ion due to its success in promoting template condensation of macrocycles of this ring size. This adaption of the synthetic scheme is yield optimized $(65 \%)$ and convenient in that condensation and the reduction step was performed in situ. A solution of ethylene diamine (0.5 mL, $7.5 \mathrm{mmol})$ in a minimum amount of methanol $(10 \mathrm{~mL})$ was added drop wise over 15 minutes to the stirred solution of 2,6-diacetyl pyridine (1.224 g, $7.5 \mathrm{mmol}$ ) and $\mathrm{BaCl}_{2} .2 \mathrm{H}_{2} \mathrm{O}(0.915$ $\mathrm{g}, 3.75 \mathrm{mmol})$. The mixture was refluxed for $12 \mathrm{~h}$. Yellow solution was allowed to cool to room temperature. Solid $\mathrm{NaBH}_{4}(0.751 \mathrm{~g}, 20 \mathrm{mmol})$ was added slowly and the flask was placed in an ice bath and was stirred for 15 minutes. A second addition of $\mathrm{NaBH}_{4}(0.375 \mathrm{~g}, 10 \mathrm{mmol})$ was done and the resulting yellow-white mixture was stirred at room temperature for one hour. Evaporation of solvent under reduced pressure yielded a yellowwhite product, which was extracted with dichloromethane (DCM). Evaporation of combined extracts to dryness yielded orange oil. This oil was dissolved in $20 \mathrm{~mL}$ of methanol, and $48 \%$ hydrobromic acid (about $6 \mathrm{~mL}$ ) was added until $\mathrm{pH}$ paper tested strongly acidic.

The product was recrystallised by dissolving in a minimum amount of hot water to which was added a small amount of activated carbon. After the mixture was filtered, absolute ethanol was added to incipient cloudiness while the heating and stirring were maintained. The solution was cooled to room temperature and placed in a refrigerator for two days. The white crystalline solid (MI) was washed with ice cold ethanol and stored in a vacuum desiccators. Yield $46 \%$; M.P. $>300^{\circ} \mathrm{C}$; color white crystalline solid, reaction time $12 \mathrm{~h}$; Anal. Calcd for $\mathrm{C}_{22} \mathrm{H}_{38} \mathrm{Br}_{4} \mathrm{~N}_{6}$ : C, 37.42; H, 5.42; Br, 45.26; N, 11.90. Found: C, 37.25; $\mathrm{H}, 5.49$; N, 11.82. IR $\left(\mathrm{KBr}, \mathrm{cm}^{-1}\right) v_{\text {max }}: 3732,2351$, 2324, 1824, 1740, 1615, 1442, 1155, $1021 \mathrm{~cm}^{-1} ;{ }^{1} \mathrm{H}$ NMR $\left(\mathrm{CDCl}_{3}\right.$, TMS, $\left.\delta \mathrm{ppm}, 500 \mathrm{MHz}\right): 7.882(\mathrm{t}, 2 \mathrm{H})$, 7.428 (d, 4H), 1.580 (s, 12H), 3.404 (qt, 8H), 4.698 (m, $4 \mathrm{H}) ;{ }^{13} \mathrm{C} \mathrm{NMR}\left(\mathrm{CDCl}_{3}, \delta \mathrm{ppm}, 500 \mathrm{MHz}\right): 14.53$, 40.29, 57.37, 120.85, 139.07, 153.26; UV-Visble: 202, $260 \mathrm{~nm}$

\section{Preparation of Membranes}

In the present work ion sensitive membranes of the PVC matrix were fabricated according to the procedure described by Craggs et al. ${ }^{32}$. An important requirement for making PVC membranes of an ion selective sensor is that the ionophore, PVC and plasticizers and anionic additives should be soluble in some fast evaporating solvent. The ionophores, PVC, different plasticizers and anionic additives used in the present investigations were found to be sufficiently soluble in THF. Therefore, the solvent THF was used for preparing membranes. Thus, membrane cocktails were formulated by dissolving appropriate amounts of ionophores, anionic additives and plasticizers. The components were added in terms of weight percentages. After thorough dissolution, the homogeneous mixture was concentrated by evaporating THF and it was then poured into polyacrylates rings placed on a smooth glass plate. The solution should be poured gently so that bubbles are not formed. A pad of filter papers and a heavy weight are then placed on top of the ring and the assembly was left for one day to allow the tetrahydrofuran to evaporate slowly at room temperature. After 24 hours of evaporation, the transparent membranes of $0.4 \mathrm{~mm}$ thickness were removed carefully from the glass plate and glued to one end of pyrex glass tube. It is known that the sensitivity, linearity and selectivity of ion selective sensor depend significantly on the membrane composition. Thus, optimization was performed after a good deal of experimentation to provide 
membranes, which generate reproducible and stable potentials. The membranes having only PVC as membrane ingredient (dummy membranes) have also been prepared to observe whether any background potentials being produced due to binding material or not.

\section{Preparation of Sandwich Membranes}

Ion-selective electrode membranes were cast from above mentioned procedure. The blank membranes (without ionophore) were also prepared having same composition. The sandwich membrane was made by pressing two individual membranes (ordinarily one without ionophore and one with the same components and an additional ionophore) together immediately after blotting them individually dry with tissue paper. The obtained sandwich membrane was visibly checked for air bubbles before mounting in electrode body with the ionophore-containing segment facing the sample solution. The combined segmented membrane was then rapidly mounted on to the electrode body and immediately measured ${ }^{33,34}$.

\section{Potential Measurement}

For the determination of chloride ion, membranes were equilibrated for $48 \mathrm{~h}$ in $0.01 \mathrm{M}$ of $\mathrm{NaCl}$ solutions. The performance of the electrode was investigated by measuring its potential in $\mathrm{NaCl}$ solutions in the concentration range $1.0^{\prime} 10^{-9}-1.0^{\prime}$ $10^{-2} \mathrm{M}$. Small concentrations of $\mathrm{NaCl}$ was obtained by gradual dilution of $0.01 \mathrm{M} \mathrm{NaCl}$ solution with millipore water. The potential measurements were carried out at $25 \pm 1{ }^{\circ} \mathrm{C}$ using following cell assemblies:

$\mathrm{Ag} / \mathrm{AgCl} \mid \mathrm{KCl}($ satd) I test solution || PVC membrane I| $0.01 \mathrm{M} \mathrm{NaCl}$ I Hg/ $\mathrm{Hg}_{2} \mathrm{Cl}_{2}$ I KCl(satd)

\section{RESULTS AND DISCUSSION}

\section{Response of Different Anions}

In preliminary experiments, various PVCmembrane ion-selective electrodes with the synthesized macrocyclic ionophore (MI) were prepared and tested for different anions. The potential response of the electrodes based on MI for different anions are shown in Fig 1. The results exhibited significantly high selectivity to chloride ion over other anions. Hence, the macrocyclic ionophore (MI) was selected as a carrier for preparation of chloride sensor.

The Effect of Membrane Composition on Potential Response of the Chloride Sensor

Potential of the membranes of MI

Table 1: Potentiometric response characteristics of chloride membrane sensors based on ionophore MI

\begin{tabular}{|c|c|c|c|c|c|c|}
\hline \multirow{2}{*}{$\begin{array}{l}\text { Sensor } \\
\text { No. }\end{array}$} & \multicolumn{4}{|c|}{ Composition of Sensor Membrane (w/w, \%) } & \multirow{2}{*}{$\begin{array}{l}\text { Slope(mV } \\
\text { decade }^{-1} \\
\text { of activity) }\end{array}$} & \multirow[t]{2}{*}{ Linear Range (M) } \\
\hline & $\begin{array}{l}\text { Ionophore } \\
\text { (MI) }\end{array}$ & HTAB & Plasticizer & PVC & & \\
\hline 1 & 0 & 4 & 56, DBP & 40 & 38.4 & $4.1 \times 10^{-4}-1.0 \times 10^{-2}$ \\
\hline 2 & 12 & 0 & 54, DBP & 34 & 53.8 & $4.0 \times 10^{-6}-1.0 \times 10^{-2}$ \\
\hline 3 & 12 & 4 & 0 & 84 & 49.5 & $6.3 \times 10^{-4}-1.0 \times 10^{-2}$ \\
\hline 4 & 12 & 4 & 54, o-NPOE & 30 & 65.3 & $8.8 \times 10^{-5}-1.0 \times 10^{-2}$ \\
\hline 5 & 12 & 4 & 54, DOP & 30 & 58.0 & $6.6 \times 10^{-7}-1.0 \times 10^{-2}$ \\
\hline 6 & 12 & 4 & $54, \mathrm{BA}$ & 30 & 55.4 & $8.2 \times 10^{-5}-1.0 \times 10^{-2}$ \\
\hline 7 & 12 & 4 & 54, TBP & 30 & 57.2 & $1.9 \times 10^{-5}-1.0 \times 10^{-2}$ \\
\hline 8 & 12 & 8 & $50, \mathrm{DOP}$ & 32 & 59.8 & $7.4 \times 10^{-7}-1.0 \times 10^{-2}$ \\
\hline 9 & 12 & 2 & 54, DOP & 32 & 57.4 & $1.4 \times 10^{-6}-1.0 \times 10^{-2}$ \\
\hline 10 & 12 & 6 & 44, DOP & 40 & 59.5 & $1.7 \times 10^{-7}-1.0 \times 10^{-2}$ \\
\hline 11 & 10 & 4 & $54, \mathrm{DOP}$ & 32 & 59.2 & $4.1 \times 10^{-8}-1.0 \times 10^{-2}$ \\
\hline 12 & 8 & 4 & $54, \mathrm{DOP}$ & 34 & 58.2 & $7.5 \times 10^{-7}-1.0 \times 10^{-2}$ \\
\hline 13 & 14 & 4 & $52, \mathrm{DOP}$ & 30 & 58.8 & $1.2 \times 10^{-7}-1.0 \times 10^{-2}$ \\
\hline
\end{tabular}


investigated as a function of chloride ion activity in the range $1.0 \times 10^{-9}$ to $1.0 \times 10^{-2} \mathrm{M}$ and the results obtained are compiled in Table 1 . The electrodes

Table 2. Selectivity coefficients of chloride selective sensor no. 11 based on the membranes of (MI)

\begin{tabular}{|c|c|}
\hline Interfering & Selectivity Coefficient (-log) $\mathbf{K}^{p t}{ }_{C(B)}$ \\
\hline Ion (B) & (MPM) \\
\hline
\end{tabular}

Sensor No. 11 Sensor No. 11

\begin{tabular}{lll}
\hline $\mathrm{SCN}^{-}$ & 2.81 & 2.65 \\
$\mathrm{NO}_{2}^{-}$ & 3.12 & 3.05 \\
$\mathrm{I}^{-}$ & 3.27 & 3.08 \\
$\mathrm{~F}^{-}$ & 3.28 & 3.83 \\
$\mathrm{Br}$ & 3.55 & 5.38 \\
$\mathrm{CH}_{3} \mathrm{COO}^{-}$ & 3.63 & 3.55 \\
$\mathrm{NO}_{3}{ }^{-}$ & 3.70 & 3.51 \\
$\mathrm{OH}^{-}$ & 3.93 & 3.82 \\
$\mathrm{HCO}^{-}$ & 4.19 & 4.08 \\
$\mathrm{CN}^{-}$ & 4.24 & 4.41 \\
$\mathrm{HPO}_{4}{ }^{2-}$ & 4.52 & 4.20 \\
$\mathrm{Sal}^{-}$ & 4.62 & 4.98 \\
$\mathrm{Cit}^{3-}$ & 4.96 & 4.87 \\
$\mathrm{SO}_{4}{ }^{2-}$ & 5.14 & 5.18 \\
$\mathrm{C}_{2}{ }^{2-}$ & 5.18 & 5.02 \\
$\mathrm{ClO}_{4}^{-}$ & 5.20 & 5.11 \\
\hline
\end{tabular}

with no carrier (containing PVC, plasticizer and HTAB) displayed insignificant sensitivity towards chloride. The influence of plasticizer on the response characteristics of the chloride electrodes was investigated by using five plasticizers of different polarities including DBP, o-NPOE, DOP, BA and TBP. The sensor no. 3 having membrane without plasticizer exhibits a narrow working concentration range of $10^{-4}$ to $10^{-2} \mathrm{M}$ with a sub Nernstian slope. Improvement in sensors performance was observed by the addition of plasticizer. Among the several membranes tested for each of the carriers, the membranes incorporating DOP showed better potentiometric responses, i.e., higher sensitivity and wider linearity of the calibration plots (sensor no. 11, Table 1).

The addition of lipophilic cationic additive in anion selective membranes is necessary to introduce perm selectivity. The influence and concentration of the membrane additives was also investigated by incorporating HTAB into the membranes. The potentiometric sensitivity of the membranes based on both carriers was greatly improved in the presence of HTAB as a lipophilic cationic additive, compared to the membranes with no additive at all. Previous studies have shown that

Table 3: Formation constant values of various ions for $\mathrm{Cl}$ " selective membrane based on [MI]

\begin{tabular}{lccc}
\hline Interfering lons & Formation Constant $\left(\log \boldsymbol{\beta}_{\mathrm{ILn}}\right)$ & Interfering Ions & Formation Constant $\left(\log \boldsymbol{\beta}_{\mathrm{ILn} n}\right)$ \\
\hline $\mathrm{Cl}^{-}$ & 8.25 & $\mathrm{~F}^{-}$ & 2.28 \\
$\mathrm{NO}_{3}^{-}$ & 4.95 & $\mathrm{OH}^{-}$ & 4.08 \\
$\mathrm{HPO}_{4}^{2-}$ & 3.11 & $\mathrm{Br}^{-}$ & 5.00 \\
$\mathrm{Cit}^{-{ }^{-}}$ & 2.43 & $\mathrm{SO}_{4}^{2-}$ & 2.05 \\
$\mathrm{HCO}_{3}^{-}$ & 3.62 & $\mathrm{SCN}^{-}$ & 5.08 \\
$\mathrm{CH}_{3} \mathrm{COO}^{-}$ & 4.66 & $\mathrm{CN}^{-}$ & 3.28 \\
$\mathrm{C}_{2}{ }_{4}^{2-}$ & 2.85 & $\mathrm{Sal}^{-}$ & 4.25 \\
$\mathrm{I}^{-}$ & 5.12 & $\mathrm{ClO}_{4}^{-}$ & 2.07 \\
\hline
\end{tabular}

Table 4: Potentiometric determination of chloride ion in soil water samples (mean \pm S.D., $n=3$ )

\begin{tabular}{lcc}
\hline Added (mg/L) & Found (mg/L) & \% Recovery \\
\hline 250 & $236 \pm 0.3$ & 94.4 \\
500 & $481 \pm 0.7$ & 96.2 \\
1000 & $973 \pm 1.0$ & 97.3 \\
\hline
\end{tabular}

there is an optimal concentration of lipophilic ionic additives in the membranes and that gives the best electrode performance ${ }^{35}$. The effect of HTAB concentration in the membrane was investigated at several additive/ionophore mole ratios. The sensors with $\mathrm{HTAB} / \mathrm{MI}$ mole ratios of $\sim 0.55$ for both of the carriers exhibited maximum sensitivity over a wide range of chloride concentration. 


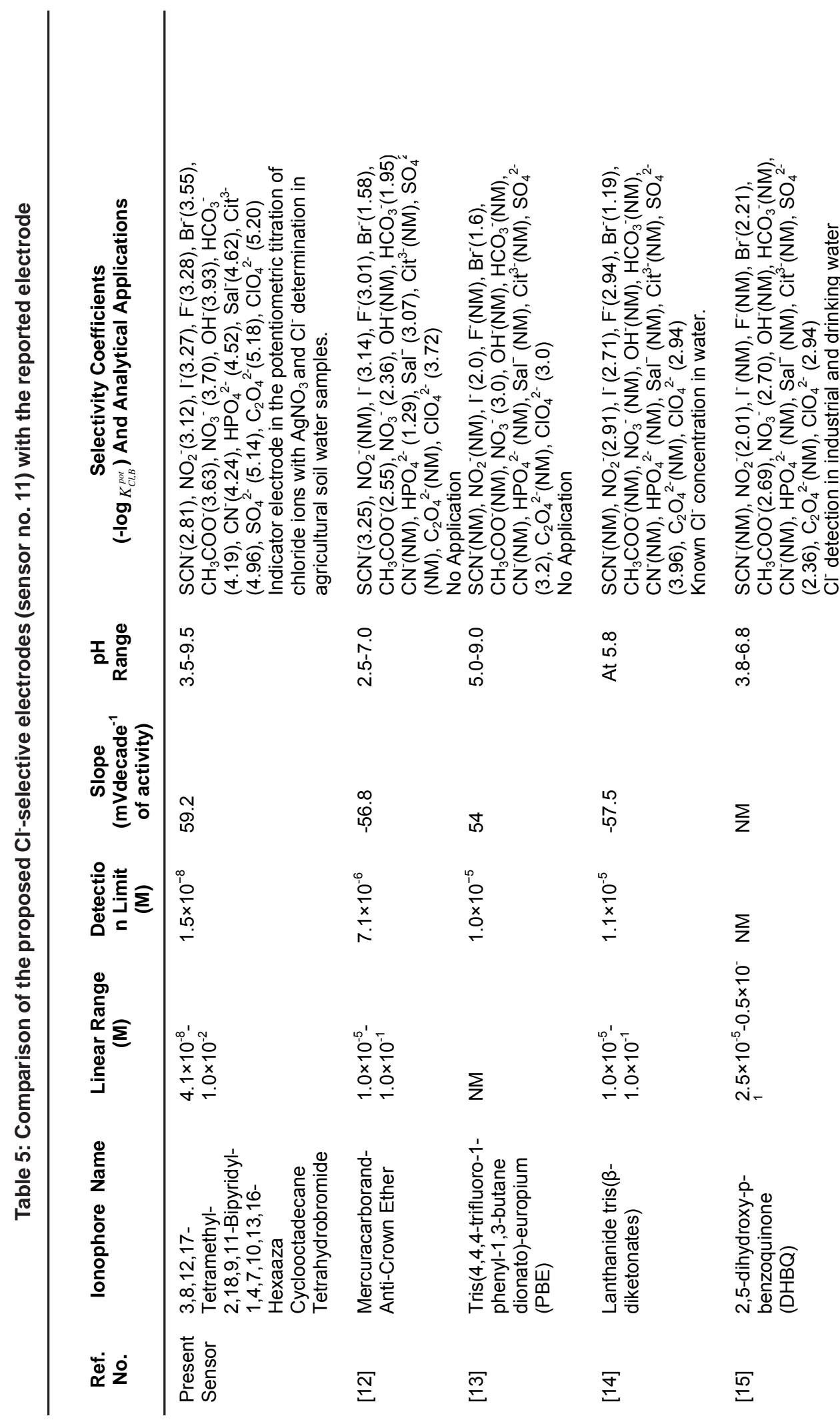



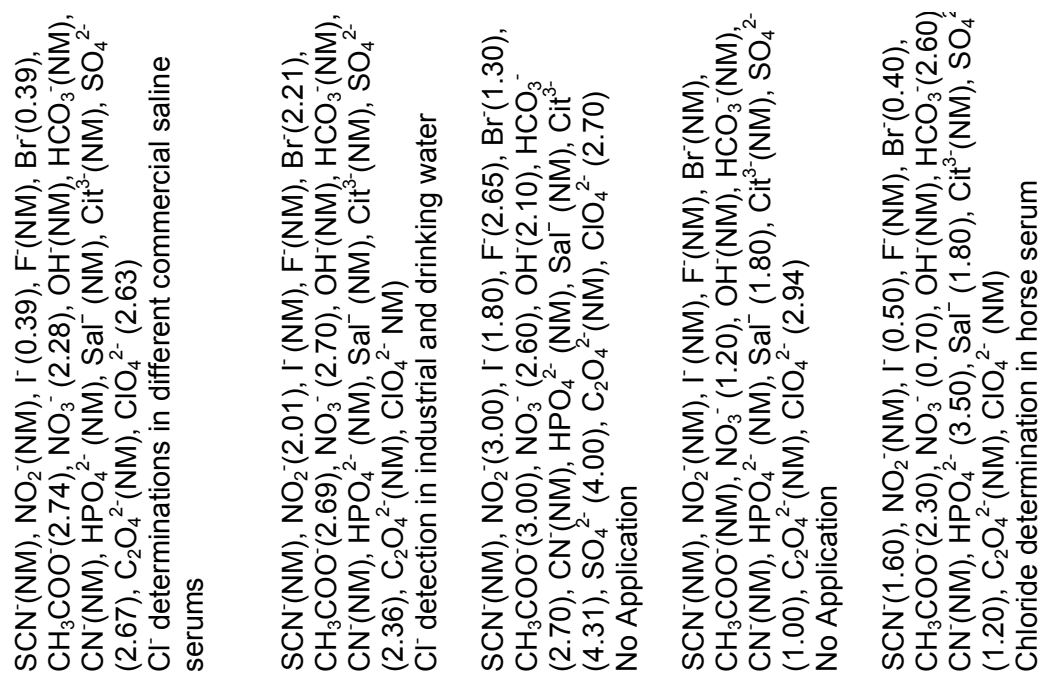

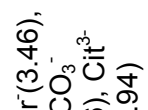

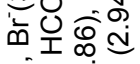

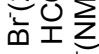

$\sum_{i} \sum_{i}$

نं

$\sum_{i=1}^{\infty} \sum_{0}^{+\infty}$

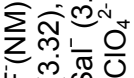

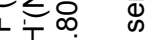

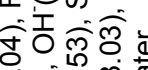

过过

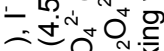

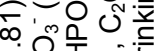

mㅍㅊㅎㅁ

유ㅇㅝㅝ

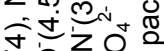
才。乙次

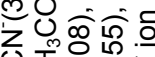
U ড

$\sum$

$\begin{array}{ll}0 & 0 \\ \dot{D} & 0 \\ \infty & m \\ \dot{N} & m\end{array}$

के
$\dot{1}$
$m$

$\sum \quad \frac{0}{\frac{\pi}{\pi}}$

0
$\infty$
1
1
0

$\sum$

î

@i



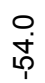

مீ

产

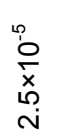

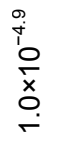

0
0
$\frac{0}{x}$
0
0
0

io

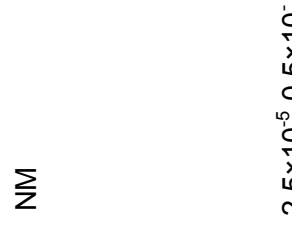

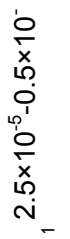

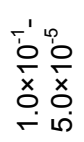

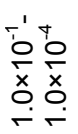

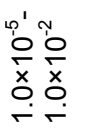

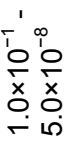

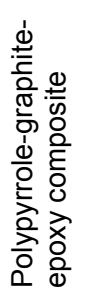

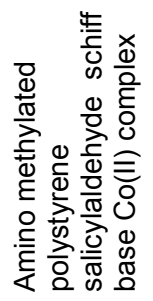

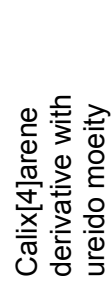

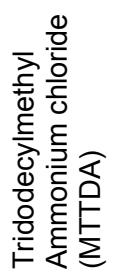

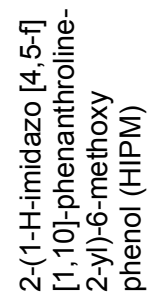

$\stackrel{\Xi}{\underline{ }}$

$\stackrel{\Sigma}{\Xi}$

$\stackrel{\infty}{=}$

হั.

$\overline{\underline{\underline{v}}}$

్ำ 
The Dynamic Response Time and Life Time of the Proposed Electrode

Dynamic response time is an important factor for chloride sensitive sensors. In this study, the practical response time has been recorded (for sensor no. 11) by changing solutions with different $\mathrm{Cl}$ concentrations. The measurement sequence was from the lower $\left(1.0 \times 10^{18} \mathrm{M}\right)$ to the higher $(1.0$ $\times 10^{\prime 2} \mathrm{M}$ ) concentration. The resulting data shows that the time needed to reach a potential with in \pm $1.0 \mathrm{mV}$ of the final equilibrium value after successive immersion of a series of $\mathrm{Cl}^{-}$solution, each having a tenfold difference in concentration is only $14 \mathrm{~s}$.

To evaluate the reversibility of the electrode, a similar procedure in the opposite direction was adopted. The measurements have been performed in the sequence of high-to-low from $\left(1.0 \times 10^{-2}-1.0 \times 10^{-6} \mathrm{M}\right)$ sample concentrations. The results showed that, the potentiometric response of the electrodes was reversible; although the time needed to reach equilibrium values (34 s) was

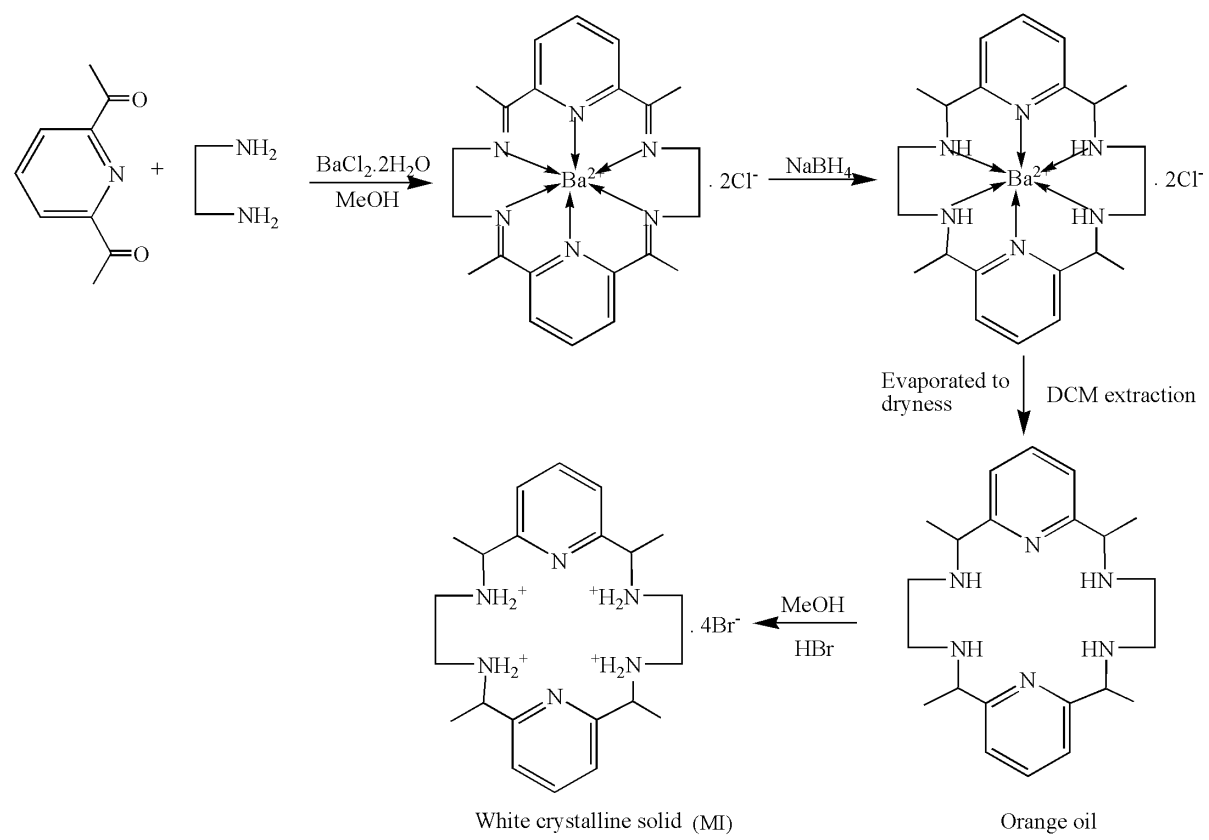

Scheme 1: Synthesis of macrocyclic ionophore (MI)

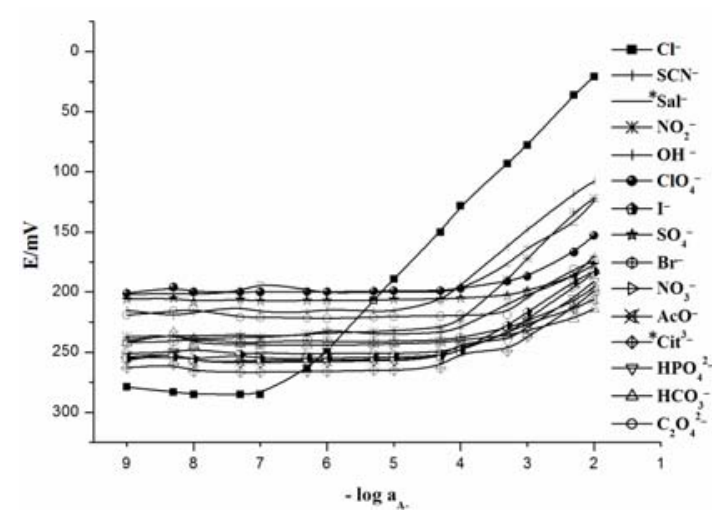

Fig. 1: Potential responses of ion-selective membrane sensor based MI for various anions *(Sal ${ }^{-}$is salicylate and $\mathrm{Cit}^{3-}$ is citrate)

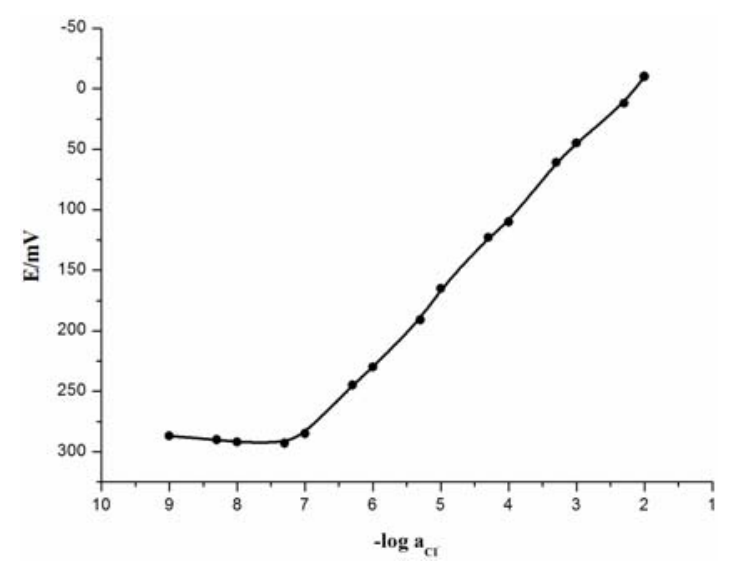

Fig. 2: Calibration plot of chloride-selective sensors based on MI ionophore 


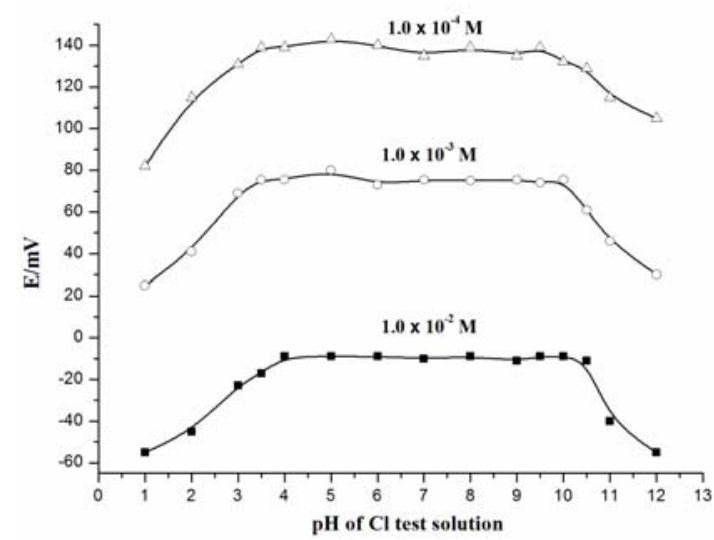

Fig. 3: Effect of $\mathrm{pH}$ on potential response of the chloride ion-selective sensors

longer than that of low-to high sample concentrations. The life time of proposed sensor is around eight weeks as potentiometric characteristics of the sensor remain almost constant with in this period of time.

\section{Calibration Characteristics}

Among the different membrane compositions, membranes with MI/HTAB/DOP/PVC in (w/w, \%) 10/4/54/32 showed highest sensitivity and widest linear range and were selected as the optimum composition for further studies (Fig. 2). These sensors exhibit the maximum working concentration range of $4.1 \times 10^{-8}$ to $1.0 \times 10^{-2} \mathrm{M}$, detection limit $1.5 \times 10^{-8} \mathrm{M}$ with a slope of $59.2 \pm 0.2$ $\mathrm{mVdecade}^{-1}$ of activity (Sensor no. 11 Table 1 ). Repeated monitoring of potentials and calibration, using the same electrode over several days gave good slope reproducibility; the standard deviation (S.D.) of slope was $0.2 \mathrm{mV}$ decade ${ }^{-1}$ activity $(\mathrm{N}=3)$.

\section{The influence of $\mathrm{pH}$ on electrode's parameters}

The $\mathrm{pH}$ dependence of the electrode potential was investigated in over the $\mathrm{pH}$ range of 1-12 for $10^{-2} \mathrm{M}, 10^{-3} \mathrm{M}$ and $10^{-4} \mathrm{M}^{-} \mathrm{Cl}^{-}$ion solutions. The potentiometric response of the chloride sensor was found to be sensitive to $\mathrm{pH}$ changes. $\mathrm{pH}$ was adjusted by the addition of $0.01 \mathrm{M}$ nitric acid and sodium hydroxide. The results given in Fig. 3 show that the potential response remains constant over the $\mathrm{pH}$ range $\sim 3.5-9.5$ and the same can be taken as the working $\mathrm{pH}$ range of the electrode. The

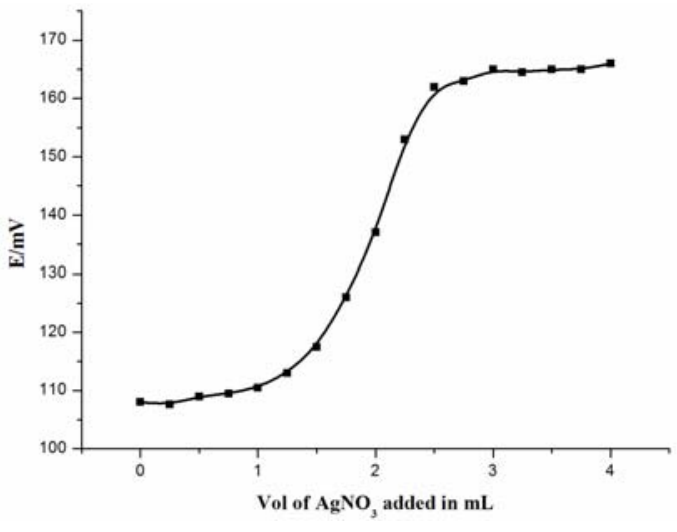

Fig. 4: Potentiometric titration curve for $20 \mathrm{~mL}$ of $1.0 \times 10^{-4} \mathrm{M} \mathrm{NaCl}_{\text {with }} 1.0 \times 10^{-3} \mathrm{M} \mathrm{AgNO}_{3}$ using the proposed sensor (no. 11)

significant change in potential response observed at a deviation at $\mathrm{pH}$ values $<3.5$, can be due to simultaneous response of the electrode to the oppositely charged $\mathrm{H}_{3} \mathrm{O}^{+}$and $\mathrm{Cl}^{-}$ions. The contribution of $\mathrm{H}_{3} \mathrm{O}^{+}$to potential response counteracts that of $\mathrm{Cl}^{-}$ions. The observed potential drift at high $\mathrm{pH}$ values could be due to response of sensor to $\mathrm{OH}^{-}$ions.

\section{Anions Effect on Sensor Selectivity}

Selectivity is an important characteristic of a sensor that delineates the extent to which the device may be used in the estimation of analyte ion in the presence of other ions and extent of utility of any sensor in real sample measurement. In this work, the selectivity coefficients of the sensors toward different anionic species $\left(A^{n-}\right)$ were evaluated by using both the matched potential method (MPM) ${ }^{36,37}$ and the fixed interference method $(\mathrm{FIM})^{38}$.

In the MPM, the selectivity coefficient $\left(K_{C l, B}^{P o t}\right)$ was determined by measuring the change in potential upon increasing the primary ion $\left(\mathrm{Cl}^{-}\right)$ activity from an initial value of $a_{\mathrm{Cl}}$ to $\beta_{\mathrm{Cl}}^{\prime}$ and $a_{\mathrm{B}}$ represents the activity of interfering ion added to the reference solution of primary ion of activity $a_{\mathrm{Cl}}$ which also brings about same potential change. It is given by expression:

$$
K_{C l, B}^{p o t}=\frac{\Delta a_{C l}}{a_{B}}=\frac{a_{C l}^{\prime}-a_{C l}}{a_{B}}
$$


In the present studies $a_{\mathrm{Cl}}$ and $a^{\prime}{ }_{\mathrm{Cl}}$ were kept at $1.0 \times 10^{-4}$ and $1.0 \times 10^{-3} \mathrm{M} \mathrm{Cl}^{-}$and $\mathrm{a}_{\mathrm{B}}$ was experimentally determined. FIM is the most widely used procedure as per IUPAC recommendation for determining selectivity coefficients ${ }^{39}$. In the FIM, the selectivity coefficient was evaluated from potential measurement on solutions containing a fixed concentration of interfering ion $\left(1.0 \times 10^{-2} \mathrm{M}\right)$ and varying amount of $\mathrm{Cl}^{-}$ions. The values of selectivity coefficient so determined are compiled in Table 2. A value of selectivity coefficient equal or greater than to 1.0 indicates equal response to both primary ion and interfering ions. A value smaller than 1.0 shows that the sensor is selective to the primary ion over the interfering ion. It is seen from the Table 2 , that the selectivity coefficients determined by both the methods are sufficiently smaller than 1.0 indicating that the present sensors are significantly selective to chloride ion over all the interfering ions. Most of the interfering ions showed low values of selectivity coefficients $\left(\sim 10^{-3}-10^{-4}\right)$, indicating no or minimum interference in the performance of the electrode assembly.

\section{Determination of Formation Constant}

Formation constant of the ion-ionophore complex within the membrane phase is a very important parameter that dictates the practical selectivity of the sensor. In this method, two membrane segments are fused together, with only one containing the ionophore, to give a concentration-polarized sandwich membrane. A membrane potential measurement of this transient condition reveals the ion activity ratio at both interfaces, which translates into the apparent binding constants of the ion-ionophore complex ${ }^{40}$. In this method complex formation constants obtained by neglecting ion pairing because ionpairing effects are relatively nonspecific i.e, all ion pair formation constants have approximately the same value. As reported, the membrane potential $E_{M}$ is determined by subtracting the cell potential for a membrane without ionophore from that for the sandwich membrane. The formation constant is then calculated from the following equation 2 :

$$
\beta_{I L_{n}}=\left(L_{T}-\frac{n R_{T}}{Z_{I}}\right)^{-n} \exp \left(\frac{E_{M} Z_{I} F}{R T}\right)
$$

Where $L_{T}$ is the total concentration of ionophore in the membrane segment, $R_{\mathrm{T}}$ is the concentration of lipophilic ionic site additives, $n$ is the ion-ionophore complex stoichiometry, and $R, T$ and $F$ are the gas constant, the absolute temperature, and the Faraday constant. The ion carries a charge of $z_{1}$. The determined formation constants $\left(\log \beta_{\mathrm{ILn}}\right.$ ) for the examined different complexes were recorded in Table 3. The elapsed time between sandwich fusion and exposure to electrolyte was typically $<1 \mathrm{~min}$. The potential was recorded as the mean of the last minute of a $5 \mathrm{~min}$ measurement period in the appropriate salt solution. The potential of such sandwich membranes remains free of diffusion-induced potential drifts for about $20 \mathrm{~min}$. Standard deviations were obtained based on the measurements of sets of at least three replicate membrane disks that were made from the same parent membrane. A careful analysis of the data in Table 3 reveals that chloride ion has significant anion-binding characteristics.

\section{Analytical Applications}

The proposed chloride membrane sensor (no. 11) was found to work well under laboratory conditions. It was applied successfully as an indicator electrode in the potentiometric titration of $20 \mathrm{~mL}$ of $1.0 \times 10^{-4} \mathrm{M} \mathrm{NaCl}$ with $1.0 \times 10^{-3} \mathrm{M} \mathrm{AgNO}_{3}$ and the resulting titration curve are shown in Fig 4. As can be seen, the amount of chloride can be determined with sensor.

The analytical utility and sensitivity of the proposed membrane sensor was verified by analysis of $\mathrm{Cl}^{-}$ion from soil water samples. Four basic factors determine the amount of $\mathrm{Cl}^{-}$available to crops growing in well drained soils, the $\mathrm{Cl}^{-}$ concentration in the soil solution; atmospheric deposition of $\mathrm{Cl}^{-}$; the $\mathrm{Cl}^{-}$concentration in the irrigation water; and the content of $\mathrm{Cl}^{-}$in fertilizers and manure. As a result of their genetic characteristics, crops have different requirements and tolerance to $\mathrm{Cl}^{-}$. The amount of $\mathrm{Cl}^{-}$added to a field via the irrigation water (fresh or treated municipal effluents) depends on farm activities. Water of low to medium salinity contains $100-300$ $\mathrm{g} \mathrm{Cl}^{-} \mathrm{m}^{-3}$, whereas saline water contains $300-1200$ $\mathrm{g} \mathrm{Cl}^{-3} \mathrm{~m}^{-3(41-44)}$.

The direct potentiometric measurement 
was carried out using standard addition technique, where recovery percentage in the range 94.4 - 97.3. The result obtained for the determination of chloride ion at several concentrations is in close agreement with the known chloride content as given in Table 4. Recovery experiments were performed by repeated measurements $(n=3)$ of soil water samples containing various amounts of chloride ions.

\section{CONCLUSIONS}

We synthesize a new macrocycle as anionrecognizing ionophore 3,8,12,17-Tetramethyl2,18,9,11-Bipyridyl-1,4,7,10,13,16-Hexaaza Cyclooctadecane Tetrahydrobromide for the fabrication of potentiometric membrane and fully characterize the potentiometric performances of selective chloride ion membrane sensor. The proposed macrocylcic ionophore is found to be very useful in ISE membranes for chloride determination.
Compared with earlier sensors, the new ISE for $\mathrm{Cl}^{-}$ shows advantages as to stability, lower detection limit, high $\mathrm{pH}$ range and good selectivity. Fast response and a reasonable long-term stability to chloride ions characterize the proposed electrode. On the basis of their selectivities, this sensor is expected to be adequate for the environmental water monitoring. Present sensor no. 11 was compared with some reported chloride selective sensors (Table 5). It is seen that the selectivity, working concentration range and $\mathrm{pH}$ range of the proposed sensor toward chloride is better as compared to reported sensors.

\section{ACKNOWLEDGEMENTS}

Dr. Sameena Mehtab and Dr. Tanveer Irshad Siddiqi are grateful to Council of Scientific and Industrial Research, New Delhi, India for providing financial assistance for this work.

\section{REFERENCES}

1. Morf, W. E.; The Principles and Ion-selective Electrodes and Membrane Transport, Elsevier, Amsterdam 1981.

2. Bakker, E.; Buhlmann, P.; Pretsch, E. Chem. Rev. 1997, 97, 3083-3132

3. Oka, S.; Sibaraki, Y.; Tahara, S. Anal. Chem. 1991, 53, 588-593

4. Seiler, H. G.; Sigel, H.; Sigel, A.; Handbook on Toxicity of Inorganic Compounds; Dekker: New York 1988.

5. Huber, C.; Werner, T.; Krause, C.; Klimant, I.; Wolfbeis, O. S. Anal. Chim. Acta 1998, 364, 143-151

6. Martin, A.; Narayanaswamy, R. Sens. Actuators B 1997, 39, 330-333

7. Badr, I. H. A.; Diaz, M.; Hawthorne, M. F.; Bachas, L. G. Anal. Chem. 1999, 71, 13711377

8. Geddes, C. D. Sens. Actuators B 2001, 72, 188-195

9. Ashcroft, F. M. Ion Channels and Diseases, Academic Press: San Diego, C A, 2000

10. Oka, S.; Sibazaki, Y.; Tahara, S. Anal. Chem. 1981, 53, 588-593

11. Ozawa, S.; Miyag, H.; Shibata, Y.; Oki, N.; Kunitake, T.; Keller, W. E. Anal. Chem. 1996,

\section{8, 4149-4152}

12. Badr, I. H. A.; Diaz, M.; Hawthorne, M. F.; Bachas, L. G. Anal. Chem. 1999, 71, 13711377

13. Dzhabarov, V. I.; Knyazev, A. A.; Yu, G. G. Russian, J. Appl. Chem. 2006, 79, 18161819

14. Mahajan, R. K.; Kaur, I. K. R.; Onimaru, A.; Shinoda, S.; Tsukube, H. Anal. Chem. 2004, 76, 7354-7359

15. Sundaram, R.; Hariprasad, K. S. Ind J. Chem. Soc. 2007, 14, 451-456

16. Ivarez-Romero, G. A.; Ramrez-Silva, M. T.; Galan-Vidal, C.A.; Paez-Hernandez, M. E.; Romero-Romoc, M. A. Electroanalysis 2010, 22; 1650-1654

17. Kumar, K. G.; John, K. S.; Indra, C. J. Ind J. Chem. Soc. 2006, 13, 13-17

18. Babu, J. N.; Bhalla, V.; Kumar, M.; Mahajan, R. K.; Puri, R. K. Tetrahedron Letters 2008, 49, 2772-2775

19. Legin, A.; Makarychev-Mikhailov, S.; Kirsanov, D.; Mortensen, J.; Vlasov, Y. Anal. Chim. Acta 2004, 514, 107-113

20. Lyczewska, M.; Wojciechowski, M.; Bulska, E.; Elizabeth, A. H.; Hall, K.; Maksymiuk, A.; 
Michalska, Electroanalysis 2007, 19, 393397

21. Xiao, K. P.; Bühlmann, P.; Nishizawa, S.; Amemiya, S.; Umezawa, Y. Anal. Chem. 1997, 69, 1038-1044

22. Gupta, V. K.; Goyal, R. N.; Sharma, R. A. Electrochim. Acta 2009, 54, 4126-4132

23. Shin, J. H.; Lee, H. L.; Cho, S. H.; Ha, J.; Nam, H.; Cha, G. S. Anal. Chem. 2004, 76, 42174222

24. Singh, A. K.; Mehtab, S.; Saxena, P. Talanta, 2006, 69; 1143-1148

25. Kumar, A.; Mehtab, S.; Singh, U. P.; Aggarwal, V.; Singh, J. Electroanalysis, 2008, 20, 11861193

26. Simonneaux, G.; Maux, P. L. Coord. Chem. Rev. 2002, 228, 43-60

27. Biesaga, M.; Pyrzynska, K.; Trojanowicz, M. Talanta 2000, 51, 209-224

28. Chou, J. H.; Kosal, M. E.; Nalwa, H. S.; Rakow, N. A.; Suslick, K. S.; Kadish, K.; Smith, K.; Guilard R. (Eds.), The Porphyrin Handbook, Vol. VI; Academic Press, New York, 2000

29. Purrello, R.; Gurrieri, S.; Lauceri, R. Coord. Chem. Rev. 1999, 190, 683-706

30. Fibbioli, M.; Berger, M.; Schmidtchen, F. P.; Pretsch, E. Anal. Chem. 2000, 72, 156-160

31. Beer, P. D.; Schmitt, P. Curr. Bio. Chem. Bio.
1997, 1, 475-482

32. Craggs, A.; Keil, L.; Moody, G.J.; Thomas, J. D. R. Talanta 1975, 22, 907-910

33. Mi, Y.; Bakker, E. Anal. Chem. 1999, 71, 52795287

34. Perez, M. A.; Marin, L. P.; Quintana, J. C.; Pedram, M. Y. Sens. Actuators B, 2003, 89, 262-268

35. Schaller, U.; Bakker, E.; Spichiger, U. E.; Pretsch E. Anal. Chem. 1994, 66, 391-398

36. Umezawa, Y.; Umezawa, K.; Sato, H. Pure Appl. Chem. 1995, 67, 507-518

37. Gadzekpo, V. P.Y.; Christian, G. D. Anal. Chim. Acta 1984, 164, 279-282

38. Bakker, E.; Pretsch, E.; Bühlmann, P.; Anal. Chem. 2000, 72, 1127-1133

39. Viteri, F. J. S.; Diamond, D. Analyst, 1994, 119, 749-758

40. Shultz, M. M.; Stefanova, O. K.; Mokrov, S. B.; Mikhelson, K. N. Anal. Chem. 2002, 74, 510517

41. Goos, R. J. Crops Soils 1987, 39, 12-13

42. LaCroix, R. L.; Keeney, D. R.; Walsh, L. M. Commun. Soil Sci. Plant Anal., 1970, 1, 1-6

43. Narayanan, P. N. V. Handbook of Ammonium Chloride Fertilizer, McMillan, India, 1990

44. Krieg, D. R.; Sung, D. Commun. Soil Sci. Plant Anal. 1977, 8, 109-114. 